\title{
The time-space exchangeability of satellite retrieved relations between cloud top temperature and particle effective radius
}

\author{
I. M. Lensky ${ }^{1}$ and D. Rosenfeld ${ }^{2}$ \\ ${ }^{1}$ Department of Geography and Environmental Studies, Bar-Ilan University, Ramat-Gan, Israel \\ ${ }^{2}$ Institute of Earth Sciences, The Hebrew University of Jerusalem, Jerusalem, Israel \\ Received: 30 August 2005 - Published in Atmos. Chem. Phys. Discuss.: 22 November 2005 \\ Revised: 12 June 2006 - Accepted: 22 June 2006 - Published: 12 July 2006
}

\begin{abstract}
A 3-minute 3-km rapid scan of the METEOSAT Second Generation geostationary satellite over southern Africa was applied to tracking the evolution of cloud top temperature $(T)$ and particle effective radius $\left(r_{e}\right)$ of convective elements. The evolution of $T-r_{e}$ relations showed little dependence on time, leaving $r_{e}$ to depend almost exclusively on $T$. Furthermore, cloud elements that fully grew to large cumulonimbus stature had the same $T-r_{e}$ relations as other clouds in the same area with limited development that decayed without ever becoming a cumulonimbus. Therefore, a snap shot of $T-r_{e}$ relations over a cloud field provides the same relations as composed from tracking the time evolution of $T$ and $r_{e}$ of individual clouds, and then compositing them. This is the essence of exchangeability of time and space scales, i.e., ergodicity, of the $T-r_{e}$ relations for convective clouds. This property has allowed inference of the microphysical evolution of convective clouds with a snap shot from a polar orbiter. The fundamental causes for the ergodicity are suggested to be the observed stability of $r_{e}$ for a given height above cloud base in a convective cloud, and the constant renewal of growing cloud tops with cloud bubbles that replace the cloud tops with fresh cloud matter from below.
\end{abstract}

\section{Introduction}

Rosenfeld and Lensky (1998) introduced a technique that was used to gain insights into precipitation forming processes. This technique was applied to AVHRR data, and later to other polar orbiting sensors (VIRS on TRMM, GLI on ADEOS II, MODIS on Terra and Aqua). The Rosenfeld Lensky Technique (RLT) was used in many studies to assess the impact of different aerosols on clouds and precipitation (Rosenfeld, 1999, 2000; Rosenfeld et al., 2001, 2002,

Correspondence to: I. M. Lensky

(lenskyi@mail.biu.ac.il)
2004; Rosenfeld and Woodley, 2001, 2003; Ramanathan et al., 2001; Rudich et al., 2002, 2003; Tupper et al., 2004; Williams et al., 2002; Woodley et al., 2000).

The RLT is based on two assumptions:

- The evolution of cloud top effective radius $\left(r_{e}\right)$ with height (or cloud top temperature, $T$ ), observed by the satellite at a given time (snapshot) for a cloud ensemble over an area, is similar to the $T-r_{e}$ time evolution of a given cloud at one location. This is the ergodicity assumption, which means exchangeability between the time and space domains.

- The $r_{e}$ near cloud top is similar to that well within the cloud at the same height as long as precipitation does not fall through that cloud volume.

The second assumption was verified using in situ aircraft measurements (Rosenfeld and Lensky, 1998; Freud et al., 2005). This paper intends to test the ergodicity assumption using a rapid scan sequence taken by the Spinning Enhanced Visible and Infrared Imager (SEVIRI) on the European METEOSAT Second Generation (MSG) geostationary satellite. To this end, rapid scan data of convective clouds over Africa is used. This paper does not intend to focus on the reasons of the different apparent behavior of clouds in different areas or to associate it with aerosols, but rather to characterize systematic distinct behavior of clouds in different areas, and to show that different clouds in the same area have similar behavior and is steady with time.

\section{The data}

Data from the Spinning Enhanced Visible and Infrared Imager (SEVIRI) on the European METEOSAT Second Generation (MSG) geostationary satellite (Schmetz et al., 2002) is used in this study. Rapid scan data (three minutes interval, from 10:01 to 15:01 GMT) from 15 December 2003 is

Published by Copernicus GmbH on behalf of the European Geosciences Union. 


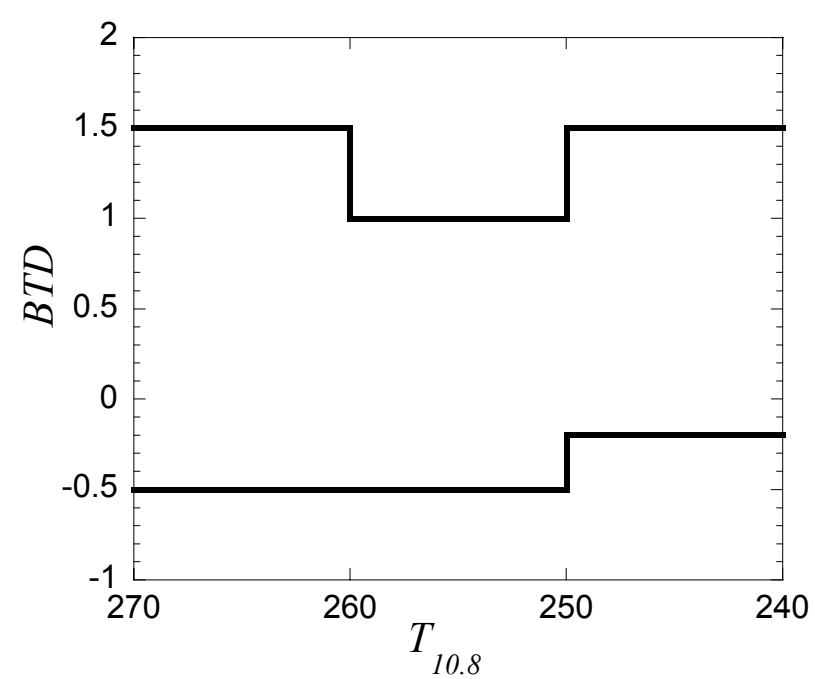

Fig. 1. Temperature dependence of the $B T D$ between 10.8 and $12.0 \mu \mathrm{m}$ channels thresholds for the cloud mask.

used to monitor convective clouds over Africa, during the pre-commissioning phase of the satellite.

Counts from the Native format data files were transformed to radiances and then to reflectances and temperatures at the solar and emissive channels respectively. The solar reflectance component of channel $4(3.9 \mu \mathrm{m})$ was calculated. For the retrieval of the cloud top effective particle size, a look up table (LUT) with entries for the satellite zenith angle, solar zenith angle, and relative azimuth was used. The LUT was calculated using SSCR (Signal Simulator for Cloud Retrieval) radiative transfer code (Nakajima and King, 1992; Nakajima, 1995) for optically thick clouds such that the surface effects can be neglected at $3.9 \mu \mathrm{m}$ (Rosenfeld et al., 2004). To make sure that only optically thick clouds are assigned an effective radius a cloud mask was used.

The cloud mask for the retrieval of $r_{e}$ consists of the following thresholds:

- Minimum reflectance threshold of $40 \%$ at the $0.6 \mu \mathrm{m}$ channel;

- Three intervals of brightness temperature difference between the 10.8 and $12.0 \mu \mathrm{m}$ channels. The first interval of -0.5 to $1.5 \mathrm{~K}$ was applied to pixels with $T_{10.8}>260 \mathrm{~K}$. The second interval of -0.5 to $1.0 \mathrm{~K}$ was applied to pixels with $260>T_{10.8}>250 \mathrm{~K}$. The third interval of -0.2 to $1.5 \mathrm{~K}$ was applied to pixels with $T_{10.8}<250 \mathrm{~K}$ (see Fig. 1).

- An interval of brightness temperature difference between the $10.8 \mu \mathrm{m}$ channel and the $8.7 \mu \mathrm{m}$ channel of -1 to $5 \mathrm{~K}$.

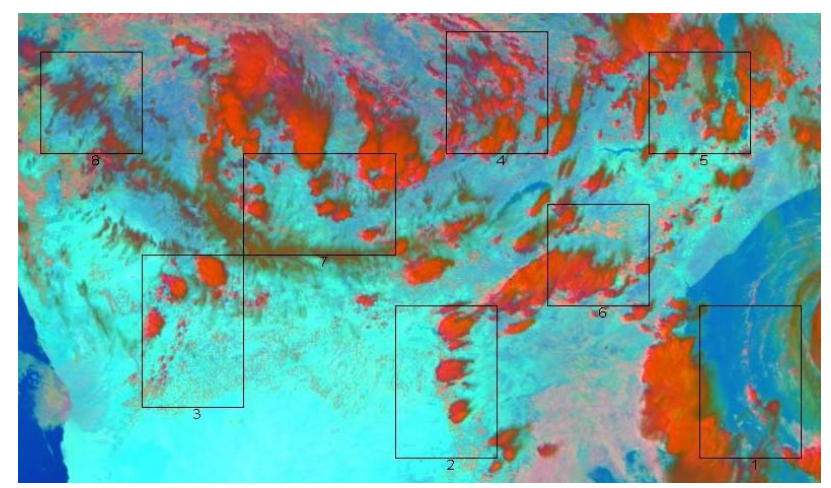

Fig. 2. MSG/SEVIRI image from 15 December 2003 13:01 GMT of convective clouds over southern Africa is shown. The color is composed of red for $0.8 \mu \mathrm{m}$ reflectance, green for $3.9 \mu \mathrm{m}$ reflectance (approximating $r_{e}$ ), and blue for $10.8 \mu \mathrm{m}$ brightness temperature. The selected areas of interest for the analysis of the time-space exchangeability of the $T-r_{e}$ are shown.

\section{Methodology}

A chain of programs was applied to the MSG raw data. In the first stage pixel data $\left(T_{10.8}\right.$ and $\left.r_{e}\right)$ from predefined areas of interest (Fig. 2) were saved for the whole data set for further analyses. In the second stage, individual cloud cells (or convective towers) were tracked. To this end we looked for local minimum of $T_{10.8}$ in a running box of 5 by 5 pixels. The cells in each area in each time step were listed in a table. These tables included the cells' location (line, pixel), $T_{10.8}$, and $r_{e}$ of the coldest pixel (cell center). The coldest (highest) pixel was selected to avoid shadows from neighboring clouds. These shadows reduce the $3.9 \mu \mathrm{m}$ solar reflectance, and erroneously enlarge the effective radius. In the third stage a cloud-tracking program was applied to track the individual cells with time and to give them an ID. The tracking routine looks for the shift of the cell center between the time steps. A maximum shift of two pixels per time step was permitted. The two pixels shift enables the tracked cell to shift to a new adjacent bubble of the same cloud. This is done to allow for long enough sequences so the time evolution of the $T-r_{e}$ plots of the individual clouds can be compared to those of a cloud cluster composed of many clouds at different stages in their life. Finally the classical $T-r_{e}$ plots of the RLT for the predefined areas in Fig. 2 were saved for all the time steps.

\section{Results}

\subsection{Time-space composition of $T-r_{e}$ relations}

About 150000 instantaneous convective cells were tracked in the 8 windows in three-minute interval between 10:01 GMT to 15:01 GMT. Figure 3 shows the classical RLT $T-r_{e}$ plots 

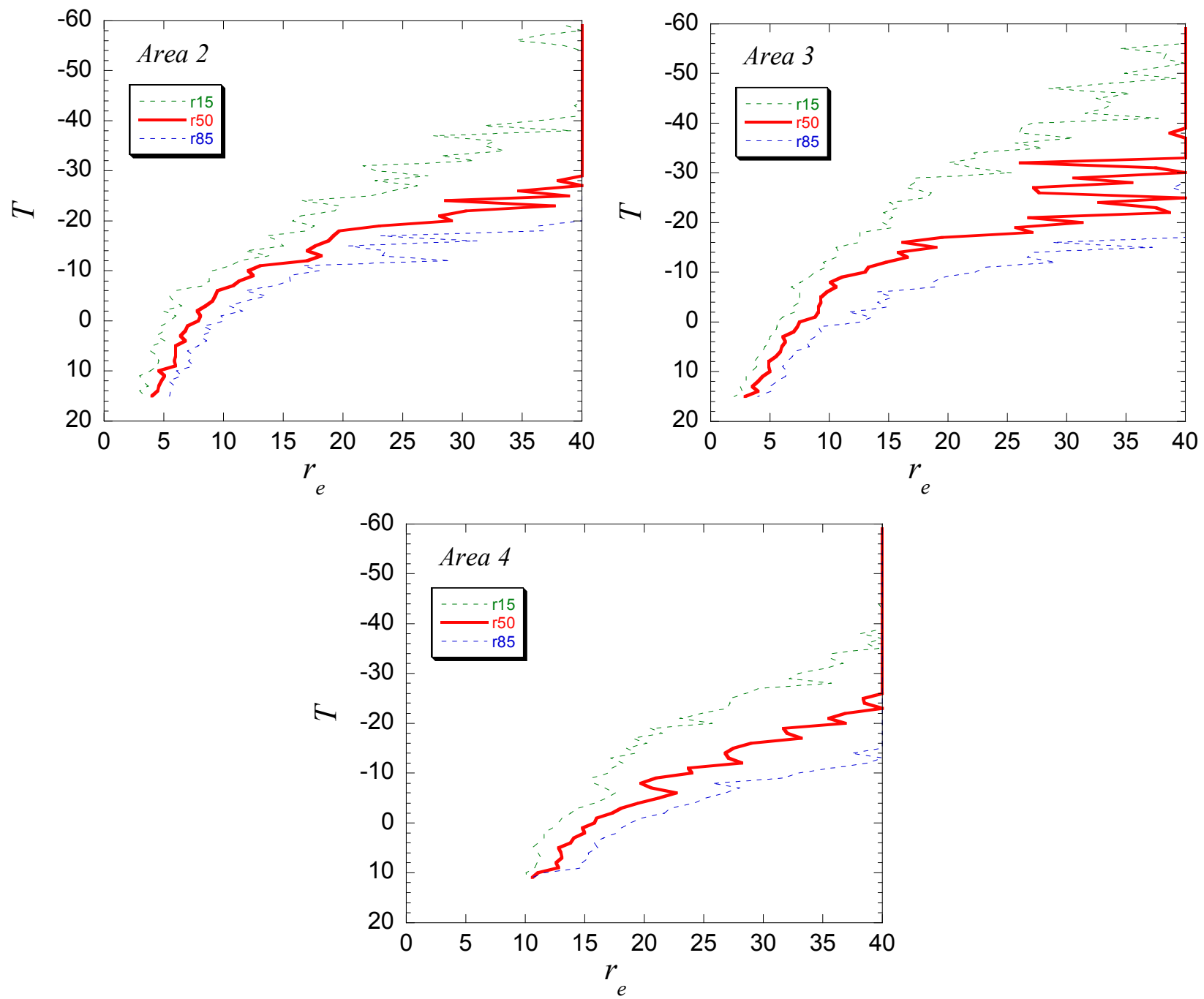

Fig. 3. Analysis of the $T-r_{e}$ relationship, for all the pixels that passed the cloud mask in areas 2, 3 and 4 from 13:01 GMT. Plotted are the 15th 50th, and 85th percentiles of the $r_{e}$ for each $1^{\circ} \mathrm{C}$ interval. The thick red line indicates the median, the dotted green line represent the 15 th percentile, and the dotted blue line represent the 85th percentile of the $r_{e}$. Areas 2 and 3 are microphysically continental, while area 4 is microphysically maritime.

of areas 2, 3 and 4 at 13:01 GMT. In this figure, the 15th, 50th (median) and 85th percentiles are presented. The $T-r_{e}$ plots are formed by calculating the median and other percentiles of the $r_{e}$ for each $1^{\circ} \mathrm{C}$ interval of $T$. If we will examine in a certain cloud cluster (where the dynamic and thermodynamic conditions are nearly uniform) two pixels with the same $T$ but with different $r_{e}$, than we can assume that the pixel with the smaller $r_{e}$ represent a more vigorous cloud. In the supercooled water and mixed phase clouds a smaller $r_{e}$ can represent also a younger cloud that developed less ice than the cloud of the second pixel. With this consideration in mind we can assume that the lower/higher percentiles represent the younger/older elements at that height. In Fig. 3, the 15th percentile will represent the younger elements, and the 85th percentile will represent the older ele- ments in a given height (temperature). Looking at the median, the effective radius of the shallowest clouds in areas 2 and 3 is very small $\left(r_{e}=5 \mu \mathrm{m}\right)$, revealing that the clouds are microphysically continental. The effective radius of cloud droplets in these clouds pass the $15 \mu \mathrm{m}$ threshold for precipitation (Lensky and Rosenfeld, 1997) only when the clouds develop to heights where $T_{10.8}<-12^{\circ} \mathrm{C}$. On the other hand, the effective radius of the shallowest clouds in area 4 is much larger $\left(r_{e}=13 \mu \mathrm{m}\right)$, and it passes the $15 \mu \mathrm{m}$ threshold for precipitation at $T_{10.8}=+5^{\circ} \mathrm{C}$. Figure 4 shows median $r_{e}$ of all the areas in Fig. 2 at 13:01. The $T-r_{e}$ curves in Fig. 4 show that areas 2, 3, and 6 are microphysically continental, that areas 1 and 4 are microphysically maritime, and that areas 5, 7 and 8 are transition between maritime and continental. 


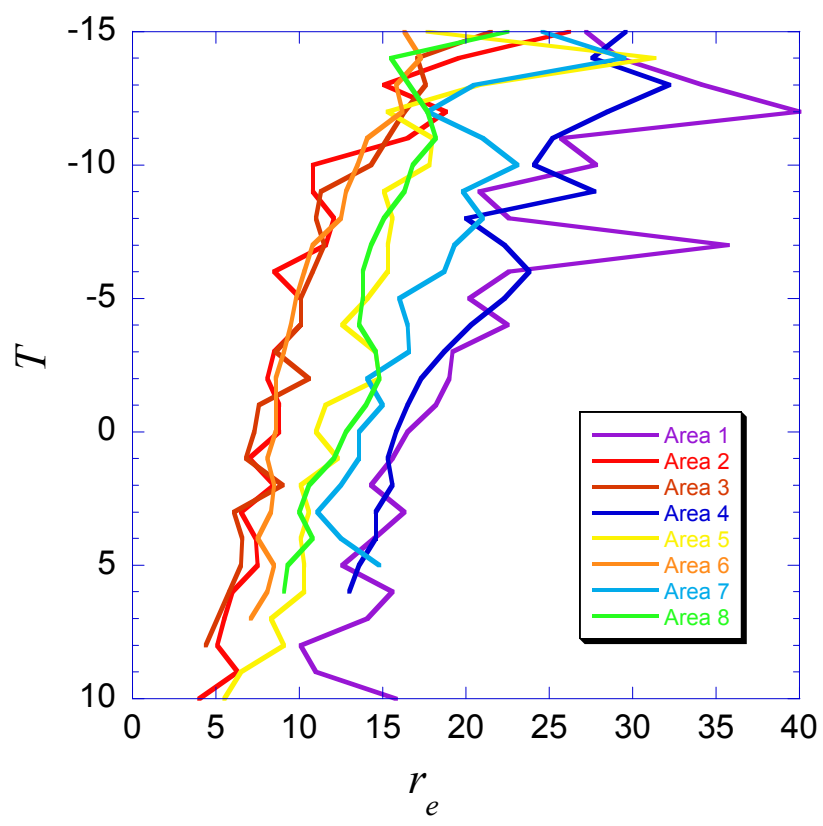

Fig. 4. The median $r_{e}$ of all the areas in Fig. 2 at 13:01. Areas 2,3 , and 6 are microphysically continental, areas 1 and 4 are microphysically maritime, and areas 5, 7 and 8 are transition between maritime and continental.

In Fig. 5 we show $T-r_{e}$ plots of the median $r_{e}$ of the same areas as in Fig. 3 at one hour intervals: 11:01, 12:01, 13:01 and 14:01 GMT. A small trend of decrease of the $r_{e}$ with time can be noticed in most of the areas. For example in areas 2 and 3 at $T=0^{\circ} \mathrm{C}$ there is a decrease of the $r_{e}$ from $10 \mu \mathrm{m}$ at 11:01 GMT to $5 \mu \mathrm{m}$ at 14:01 GMT. However it is evident from this figure that the maritime/continental behavior of the clouds in the predefined areas is clearly distinguished. For example in area 4 at the same isotherm the $r_{e}$ decreases from $20 \mu \mathrm{m}$ at 11:01 GMT to $15 \mu \mathrm{m}$ at 14:01 GMT. The decrease of the $r_{e}$ may be due to increased vigor of the convection with time from morning to the afternoon, together with the increasing of cloud base height and decreasing cloud base temperature, all slowing the growth of the $r_{e}$ with height thus contributing to increased microphysical continentality of clouds during the day. This is manifested by the shift to the left (smaller $r_{e}$ ) of the $T-r_{e}$ plots.

\subsection{The $T-r_{e}$ time evolution of individually tracked clouds}

Convective cloud development can be viewed as consecutive towers that dissipate or merge with previous cloud elements, and new towers replace them and develop some more, and so on until a fully-grown $\mathrm{Cb}$ cluster is formed in some cases, or in other cases the clouds dissipate before reaching that stature. The approach that was taken for the cloud tracking was to look for local minima of the temperature field in the cloudy pixels in each time step, and then to track these local minima from one time step to the next based on the cell location (line and column). Tracking the cloud elements results therefore in few long tracks along with many shorter ones that merged into the longest that made it all the way to the mature stage. It is analogous to a river (the long-tracked main cell) with many tributaries (the cells that merge to the primary one), but only one water way connects the initial development to the outlet of the river to the sea (the anvil of the mature storm). Figure 6 shows the time evolution of $T$ and $r_{e}$ of these longest cloud tracks. The cells were found to be very often regenerating in the same location, such that after a developing stage (decreasing $T$ and increasing $r_{e}$ ), came a drop in the $r_{e}$ and rise of the $T$ followed by another developing stage. For example, cell 30 in area 3 of Fig. 6 seems to glaciate after about 75 minutes $\left(r_{e}=40 \mu \mathrm{m}\right)$ but after about 5 minutes $r_{e}$ drops to $28 \mu \mathrm{m}$ and $T$ increases by $6^{\circ} \mathrm{C}$ (from $-38^{\circ} \mathrm{C}$ to $-32^{\circ} \mathrm{C}$ ). Maturation of the older glaciated cell segment may lead to thinning of the segment due to precipitation and evaporation. The resultant increase of the BTD between the 10.8 and $12.0 \mu \mathrm{m}$ channels causes these pixels to be rejected by the cloud mask. In such case the cell track jumps to adjacent pixels that did pass the criteria of the cloud mask. Other cases like the peaks in the first $60 \mathrm{~min}$ of cell 30 in area 3 represent regeneration of the convective bubbles that form the cloud. These succeeding developing stages follow the general $T-r_{e}$ characteristics of the area as can be seen in Fig. 7. It follows that the general characteristic $T-r_{e}$ plot of the area is built upon many regenerating cells that follow the same $T-r_{e}$ relations (confirming again the second assumption of the RLT).

The dynamic behaviors of single clouds were often very different; still their microphysical behavior remained consistent with the typical $T-r_{e}$ plot of that area. For example, note in Fig. 6 that cell number 41 in area 3 that do not make it to a $\mathrm{Cb}$ stature (lowest $T>\sim-20^{\circ} \mathrm{C}$ ) have the same $r_{e}$ for the same $T$ as clouds that become eventually fully grown as cell number $30\left(T_{30}=-60^{\circ} \mathrm{C}\right)$, in spite of the dynamical differences that determined such different fates for these two cells.

The rapid scan of the clouds microstructure allows for the first time to add the time dimension to the microphysics of clouds from space observations. The longevity of highly supercooled (i.e., $T<-10^{\circ} \mathrm{C}$ ) clouds tracked in Fig. 6 is $3-$ 4 times longer than the 10 to $15 \mathrm{~min}$ that were previously reported by observations made by repeated aircraft penetrations into tropical and subtropical microphysically continental clouds (Rosenfeld and Woodley, 1997). Also the inferred updraft velocity is smaller than observations. For example, in area 2, it took about $50 \mathrm{~min}$ for cells number 67 and 296 to reach the $r_{e}=15 \mu \mathrm{m}$ threshold (at $T=-10^{\circ} \mathrm{C}$ ). This corresponds to very low updraft of about $1.2 \mathrm{~ms}^{-1}$, whereas updrafts $>5 \mathrm{~ms}^{-1}$ were usually observed by aircraft in situ measurements (Rosenfeld and Woodley, 1997). The discrepancy between the aircraft and satellite observations can be resolved by the suggestion that the tracked cloud top is renewed frequently by new growing cloud bubbles, and the longevity 

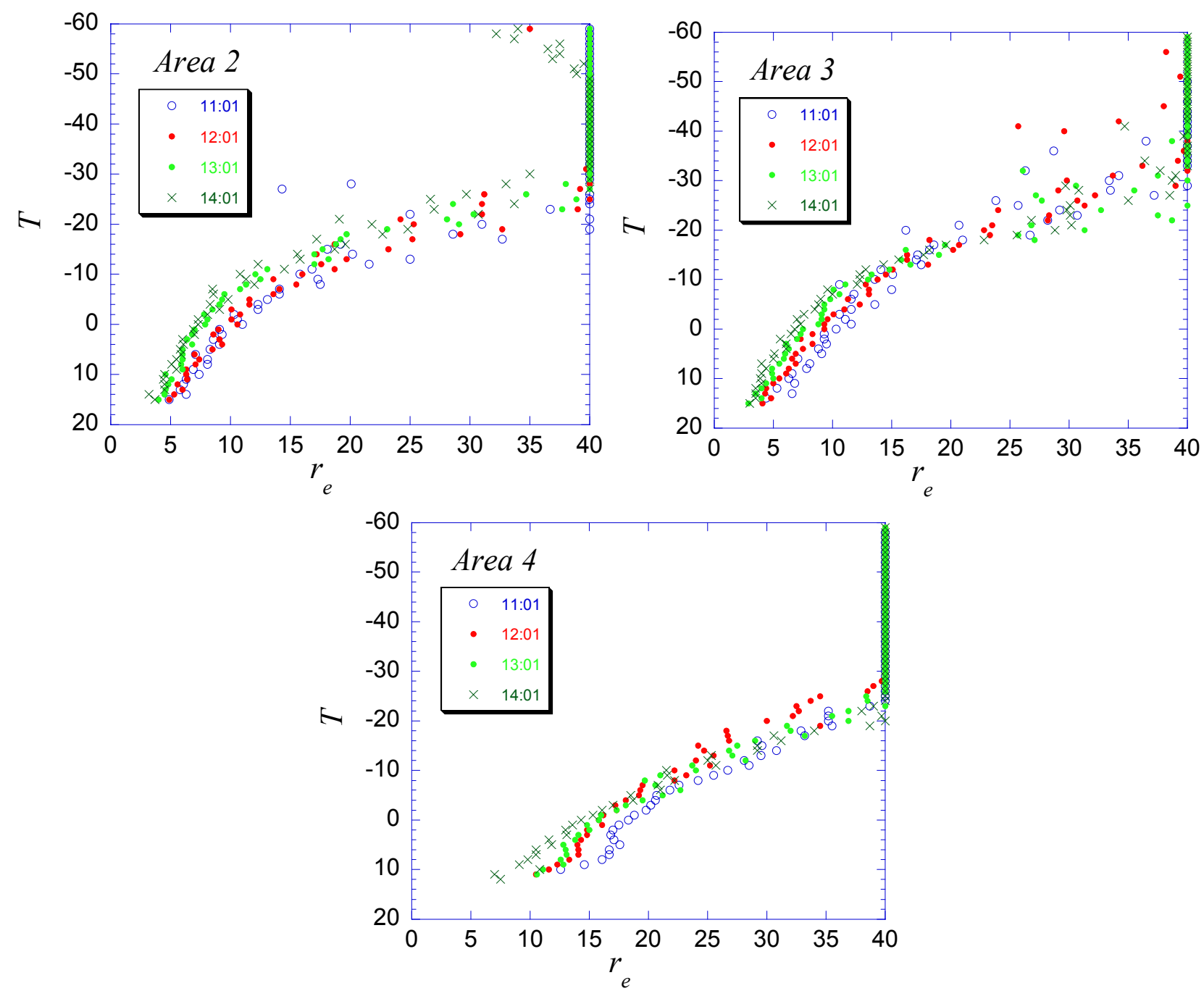

Fig. 5. Same as Fig. 3, but for the median $r_{e}$ at one-hour intervals: 11:00, 12:00, 13:00 and 14:00 GMT.

of the supercooled cloud water is a lot shorter than the outline of the cloud top. Furthermore, the effects of cloud drop coalescence to increase $r_{e}$ and evaporation to decrease $r_{e}$ nearly cancel each other and cause further stability of the $r_{e}$ as long as the cloud is not appreciably glaciated (Freud et al., 2005). The process of the cloud top renewal by sequence of bubbles along with the stability of $r_{e}$ to maturation of cloud drop distribution at a given $T$ explain the apparent lack of sensitivity of $r_{e}$ to the elapsing time within the convective cloud life cycle. The lack of time dependence of $r_{e}$ on $T$ leaves $r_{e}$ in convective elements almost exclusively as a function of $T$. This is the fundamental cause for the exchangeability of time and space, or the ergodicity of the $T-r_{e}$ relations.

\subsection{Comparing time and space dimensions}

The ergodicity assumption requires that tracking the cells and then composite back their elements should reproduce the snap shot for the cloud field to which the cells belong. This is done in Fig. 7, which shows similar $T-r_{e}$ relations for cells of vastly different time evolution, some of which are presented in Fig. 6. For example, area 2 of Fig. 7 is composed of cell number 296 of Fig. 6, which after reaching the $r_{e}=15 \mu \mathrm{m}$ threshold at $T=-10^{\circ} \mathrm{C}$ continued to develop for another $20 \mathrm{~min}$, reaching $T=-25^{\circ} \mathrm{C}$ and $r_{e}=25 \mu \mathrm{m}$, but then started to decay, and vanished after another $20 \mathrm{~min}$. It took about 20 min for cell number 30 in area 3 to cross the $0^{\circ} \mathrm{C}$ isotherm, and another $50 \mathrm{~min}$ to start glaciate at $T=-30^{\circ} \mathrm{C}$, and vanished more then one hour later. When plotting on Fig. 7 the $T-r_{e}$ relations of these cell tracks while ignoring the time dimension we practically reconstruct the $T-r_{e}$ plots 

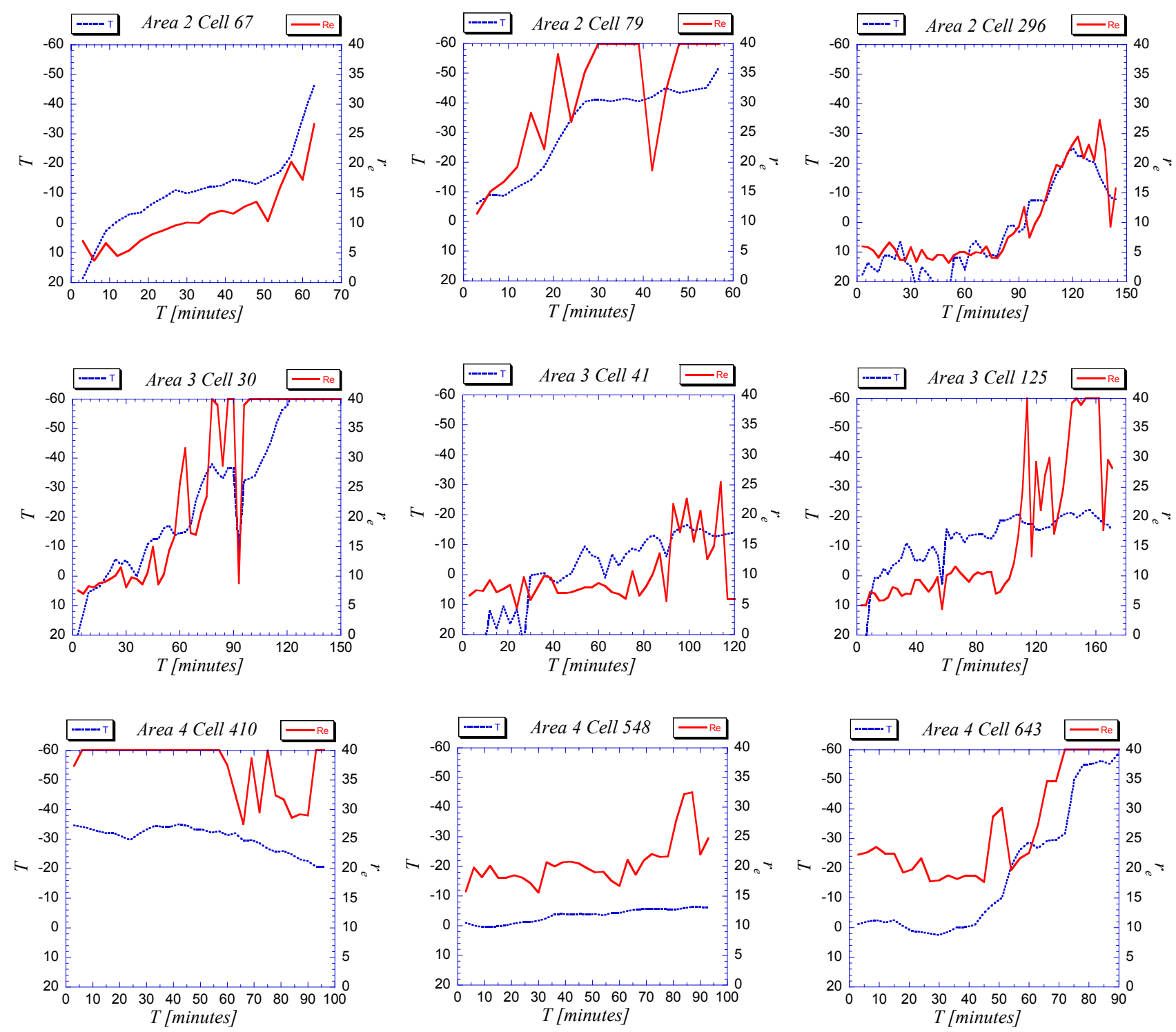

Fig. 6. Time evolution of $T$ (dotted blue line) and $r_{e}$ (solid red line) of the cells' coldest pixel of some of the longer tracked convective cells in areas 2,3 and 4.

of the areas in Fig. 3, which is repeated as the lines in the background of Fig. 7. This confirms the ergodicity of the cloud field during this case, which is all the available data so far from the pre-commissioning rapid scan of the MSG satellite.

Strictly speaking, the ergodiciy assumption is valid only for stationary conditions, i.e., not allowing systematic changes in the cloud field properties with time. However, the ergodicity approximation would be still valid if the time scale of the growing phase of convective elements is short with respect to the time scale of the changes in the cloud population properties. The time scale for growth of individual convective elements is 20 to $40 \mathrm{~min}$. For example, an air parcels would ascend at the modest updraft velocity of $5 \mathrm{~ms}^{-1}$ through a $10-\mathrm{km}$ deep cloud within $33 \mathrm{~min}$. This time scale is much shorter than the diurnal time scale which affects the general properties of the cloud field. Therefore, the ergodiciy assumption remains generally valid, except for areas of strong gradients in the properties such as coast lines, strong aerosol gradients or over sharp transitions between different air masses.

\section{Conclusions}

The unique MSG rapid scan data enables us to track the microphysical evolution of the tops of individual convective 
Area 2

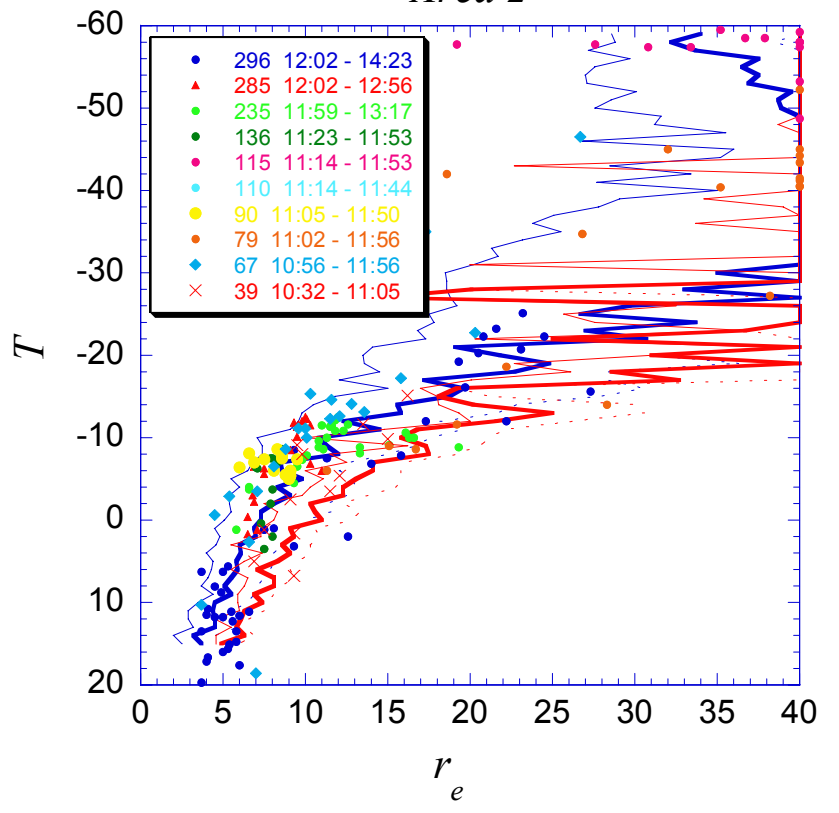

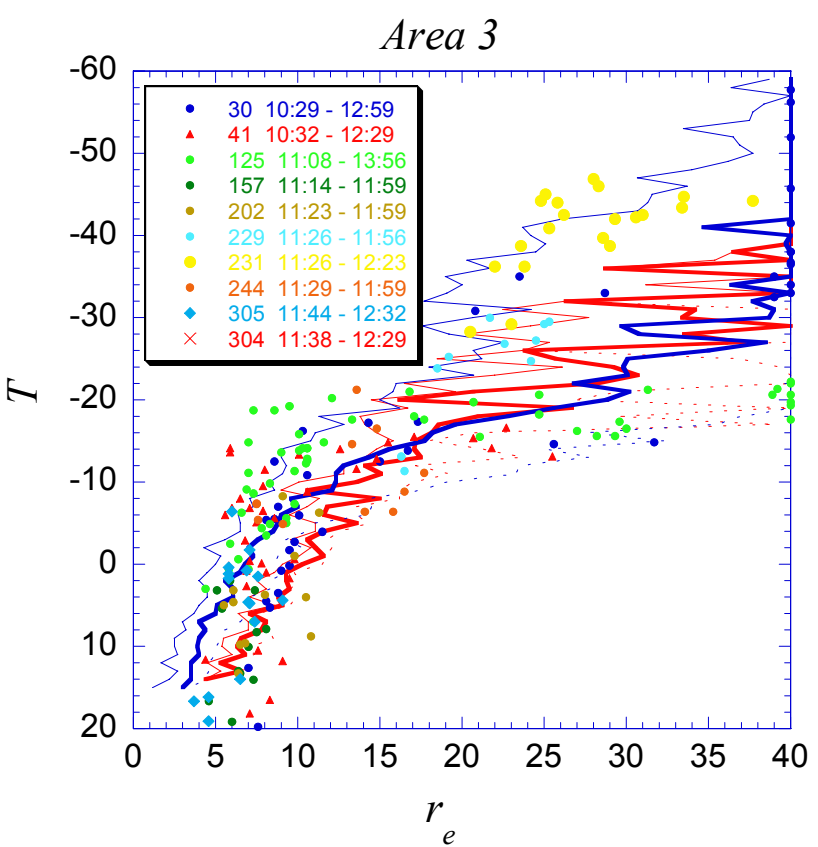

Area 4

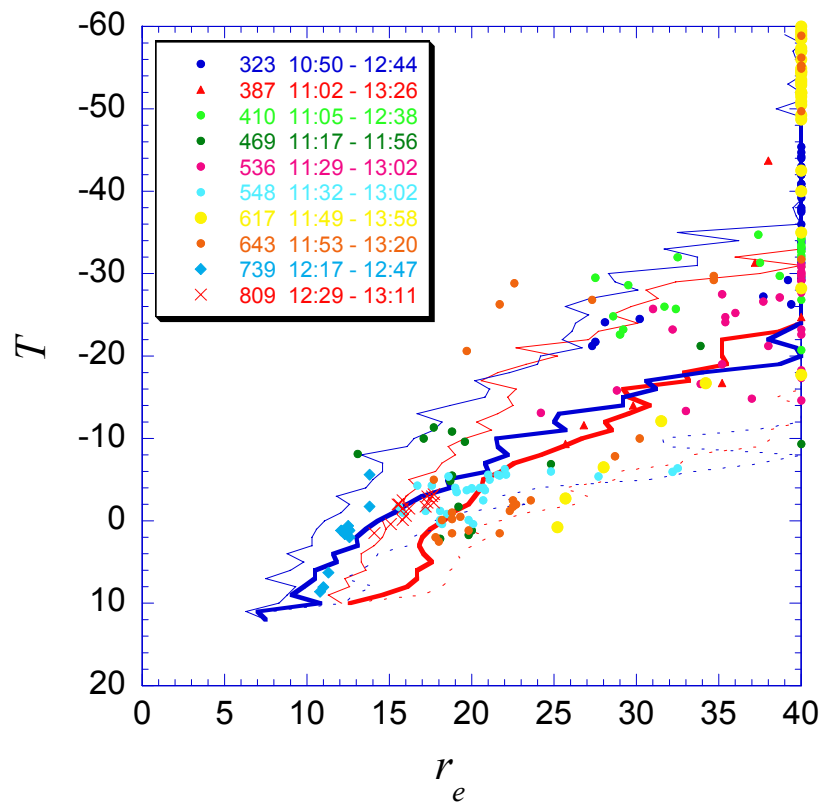

Fig. 7. Scatter plot of the $T-r_{e}$ of the coldest pixel in some of the convective cells in areas 2, 3 and 4. Some of these cells are shown in Fig. 6. The cell number as well as the starting and ending time of the cells is displayed. An overlay of the median (thick solid line), the 15th (thin solid line) and the 85th (dotted line) percentiles of 11:01 (red) and 14:01 (blue) are added.

cloud elements in different areas. It has been shown here that individual clouds follow the general pattern of the $T-r_{e}$ plot that characterizes the convective cloud cluster in its specific area, although the individual clouds may be very different dynamically. The single clouds, each in its stage: young, mature or dissipating, join to build the $T-r_{e}$ plot of the cluster. We showed that the rate and duration of processes such as diffusional growth and duration of supercooled phase could be inferred from the time sequence, but their variation in duration has little effect on the dependency of $r_{e}$ on $T$. The resultant $T-r_{e}$ relations of a convective cloud field is stable over time, and depends mainly on the thermodynamic and aerosol properties of the air mass. For example, the diurnal increase of instability is associated with a small decrease of 
the $r_{e}$ for a given $T$ in the afternoon hours. This change occurs at much longer time scales than the lifecycle times of the individual cloud elements, and hence does not violate the ergodicity assumption. Furthermore, this supports the validity of using of the ergodicity assumption for detecting variability in the $T-r_{e}$ relations for a cloud field under relatively slowly varying conditions.

The validity of the ergodicity assumption is at the basis of the inference of vertical microphysical evolution of convective cloud elements, using a snap shot of convective cloud field (Rosenfeld and Lensky, 1998). This is important because of the much greater resolution of polar satellites that can take only snap shots. The validation of the ergodicity assumption provides a more solid basis for using these satellites snap shots for inferring the microphysical evolution of growing convective cloud elements.

Acknowledgements. The authors thank EUMETSAT for providing the unique MSG rapid scan data set that made this study possible. This study was partially supported by the Israeli Ministry of Science.

Edited by: Y. Balkanski

\section{References}

Freud, E., Rosenfeld, D., Andreae, M. O., Costa, A. A., and Artaxo, P.: Robust relations between $\mathrm{CCN}$ and the vertical evolution of cloud drop size distribution in deep convective clouds, Atmos. Chem. Phys. Discuss., 5, 10 155-10 195, 2005.

Lensky, I. M. and Rosenfeld, D.: Estimation of precipitation area and rain intensity based on the microphysical properties retrieved from NOAA AVHRR data, J. Appl. Meteor., 36, 234-242, 1997.

Nakajima, T. and King, M. D.: Asymptotic theory for optically thick layers, Appl. Opt., 31, 7669-7683, 1992.

Nakajima, T. Y. and Nakajima, T.: Wide-area determination of cloud microphysical properties from NOAA AVHRR measurements for FIRE and ASTEX regions, J. Atmos. Sci., 52, 40434059, 1995.

Ramanathan, V., Crutzen, P. J., Kiehl, J. T., and Rosenfeld, D.: Aerosols, Climate and the Hydrological Cycle, Science, 294, 2119-2124, 2001.

Rosenfeld, D. and Lensky, I. M.: Satellite-based insights into precipitation formation processes in continental and maritime convective clouds, Bull. Amer. Meteor. Soc., 79, 2457-2476, 1998.
Rosenfeld, D: TRMM observed first direct evidence of smoke from forest fires inhibiting rainfall, Geophys. Res. Lett., 26, 31053108, 1999.

Rosenfeld, D: Suppression of rain and snow by urban and industrial air pollution, Science, 287, 1793-1796, 2000.

Rosenfeld, D., Rudich, Y., and Lahav, R.: Desert dust suppressing: A possible desertification feedback loop, Proc. Natl. Acad. Sci. USA, 98, 5975-5980, 2001.

Rosenfeld, D. and Woodley, W. L.: Cloud microphysical observations relevance to the Texas cold-cloud conceptual seeding model, J. Wea. Mod., 29, 56-68, 1997.

Rosenfeld, D. and Woodley, W. L.: Pollution and Clouds. Physics World, Institute of Physics Publishing LTD, Dirac House, Temple Back, Bristol BS1 6BE, UK, February 2001, 33-37, 2001.

Rosenfeld, D., Lahav, R., Khain, A. P., and Pinsky, M.: The role of sea-spray in cleansing air pollution over ocean via cloud processes, Science, 297, 1667-1670, 2002.

Rosenfeld, D. and Woodley, W. L.: Closing the 50-year circle: From cloud seeding to space and back to climate change through precipitation physics, Chapter 6 of "Cloud Systems, Hurricanes, and the Tropical Rainfall Measuring Mission (TRMM)", edited by: Tao, W.-K. and Adler, R., 234pp., p. 59-80, Meteorological Monographs 51, AMS, 2003.

Rosenfeld, D., Cattani, E., Melani, S., and Levizzani, V.: Considerations on daylight operation of $1.6 \mu \mathrm{m}$ vs. $3.7 \mu \mathrm{m}$ channel on NOAA and METOP Satellites, Bull. Amer. Meteor. Soc., 85, 873-881, 2004.

Rudich, Y., Rosenfeld, D., and Khersonsky, O.: Treating clouds with a grain of salt, Geophys. Res. Lett., 29(22), doi:10.1029/2002GL016055, 2002.

Rudich, Y., Sagi, A., and Rosenfeld, D.: Influence of the Kuwait oil fires plume (1991) on the microphysical development of clouds, J. Geophys. Res., 108(D15), 4478, doi:10.1029/2003JD003472, 2003.

Schmetz, J., Pili, P., Tjemkes, S., Just, D., Kerkmann, J., Rota, S., and Ratier, A.: An Introduction to Meteosat Second Generation (MSG), Bull. Amer. Meteor. Soc., 83, 977-992, 2002.

Tupper, A., Oswalt, J. S., and Rosenfeld, D.: Satellite and radar analysis of the "volcanic" thunderstorms at $\mathrm{Mt}$ Pinatubo, Philippines, 1991, J. Geophys. Res., 110, D09204, doi:10.1029/2004JD005499, 2004.

Williams, E., Rosenfeld, D., and Madden, M.: Contrasting convective regimes over the Amazon: Implications for cloud electrification, J. Geophys. Res., 107(D20), 8082, doi:10.1029/2001JD000380, 2002.

Woodley, W. L., Rosenfeld, D., and Strautins, A.: Identification of a seeding signature in Texas using multi-spectral satellite imagery, J. Wea. Mod., 32, 37-52, 2000. 